\title{
El rey, la catedral y la expresión de un programa *
}

\author{
Manuel nuñez Rodriguez **
}

Dentro de las innumerables posibilidades que todavia ofrece el estudio de la Catedral de León, plantear el cómo se hizo ya no basta. Aquella experiencia que representaba el punto más avanzado de la cultura arquitectónica dentro de la Peninsula, estaba llamada a asumir un valor decisivo en el centro de un vasto debate. En estas circunstancias ¿qué otros propósitos vienen dictados en la Catedral de León, además de los vinculados al ambiente religioso de su época?, ¿qué brillo adicional puede aportar su promotor Alfonso $X$ ?

Cuando en el siglo XIII el occidente de Europa asistia al descrédito de la institución imperial - poco más que un vestigio simbólico de autoridad- $y$ al afianzamiento de las monarquias nacionales, la nueva Castilla que reordena su territorio, siente la necesidad de definir su pasado histórico, en la convicción de que se habian superado las incertidumbres frente al Islam. $Y$ todo ello a través de unas victorias militares en las que se entrecruza el principio de guerra santa. Aunque la pieza clave de cuanto antecede es Fernando III, Alfonso X habrá de asumir el significado histórico del nuevo proceso, para así llevar a término un proyecto ambicioso y de significados múltiples.

Uno de los capitulos más llamativos de su curriculum como hombre político, lo constituyen sus esfuerzos por alcanzar simbolos de autoridad que definan su influencia y poder en asuntos temporales. $Y$ puesto que conjurar el fantasma del poder imperial no supone escamotear su evidencia, en esta dirección universalista puso su acento Alfonso $\mathrm{X}$ a la hora de reclamar sus derechos legales a la candidatura del Imperio, apelando

\footnotetext{
* Conferencia dictada en los cursos de doctorado del Dpto. de $\mathrm{H}^{\text {a }}$ del Arte de la UNED. Mayo 1992.

** Universidad de Santiago de Compostela.
} 
a la materna sucessio. Pero los términos del debate, que intentan dar medida de la importancia que asume el nuevo reino castellano-leonés dentro de la Península, aún van más allá; este rey al que le es encomendado el gobierno por mandato divino, también desea apuntalar su posición de superioridad, como expresión de la más amplia autoridad. Su modo de entender la idea de máximo poder en aquel reino que lleva a cabo una nueva ordenación territorial, hacia referencia al plan expuesto por los tratadistas políticos de su tiempo: rex est imperator in regno suo. Sin duda, se trataba de un régimen imperial en menor escala, pero estaba dirigido a fortalecer los fundamentos teóricos de la superioridad del poder regio, en aras de una mayor fuerza a su mandato legal y en beneficio de una centralización de su autoridad; algo que, en definitiva, podria transmitir la imagen de un reino cohesionado, aunque las resistencias y oposiciones no dejarian de apreciarse entre los nobles y eclesiásticos.

En medio de tales circunstancias, el proyecto de este monarca, quien se había coronado y ordenado caballero a sí mismo, parece inseparablemente ligado con el proyecto de la Catedral de León o «historia de un compromiso"; probable efecto de una causa.

En ella habrian de culminar los nuevos modelos góticos, como evidencia de un clima ideológico nuevo donde los fundamentos religiosos o sobrenaturales legitiman los criterios de autoridad regia como emanada de Dios; legitimación dirigida a dar la imagen de un príncipe cristiano que adopta un modo de conducta grato a Dios, en la creencia de que fortaleceria tanto a la institución real, como a la propia efectividad política de aquel monarca cuyas aspiraciones imperiales «estaban teniendo costos muy gravosos en todo el reino".

Este "amador de ciencias e saberes" tiene un puesto preferente en la historiografia actual por los múltiples aspectos de su biografía, donde parece quedar elaborada la imagen del rey perfecto y cultivado, tal como le definiera el portugués $D$. Dionis: «sodes el más noble rey que ha en el mundo". Valoración que trae al recuerdo la de San Bernardo cuando calificaba a Luis VI Capeto como "el primero de los reyes".

Consciente de su significado histórico y de una voluntad por reconocer su autoridad universal, su labor va a estar encaminada a retomar los fundamentos teóricos precisos que equiparen tal superioritas, tanto en sus sueños de imperio en la península como en Alemania; posiciones que Macdonald y Valdeón consideran inseparablemente ligadas a su prestigio, en especial en el llamado "fecho del Imperio". Podría decirse que su biografia es un deseo contínuo de poner en práctica un programa de acción de logros brillantes donde queden definidas sus posiciones ideológicas, lo mismo en sus proyectos de reforma legal, como con respecto al arte. 


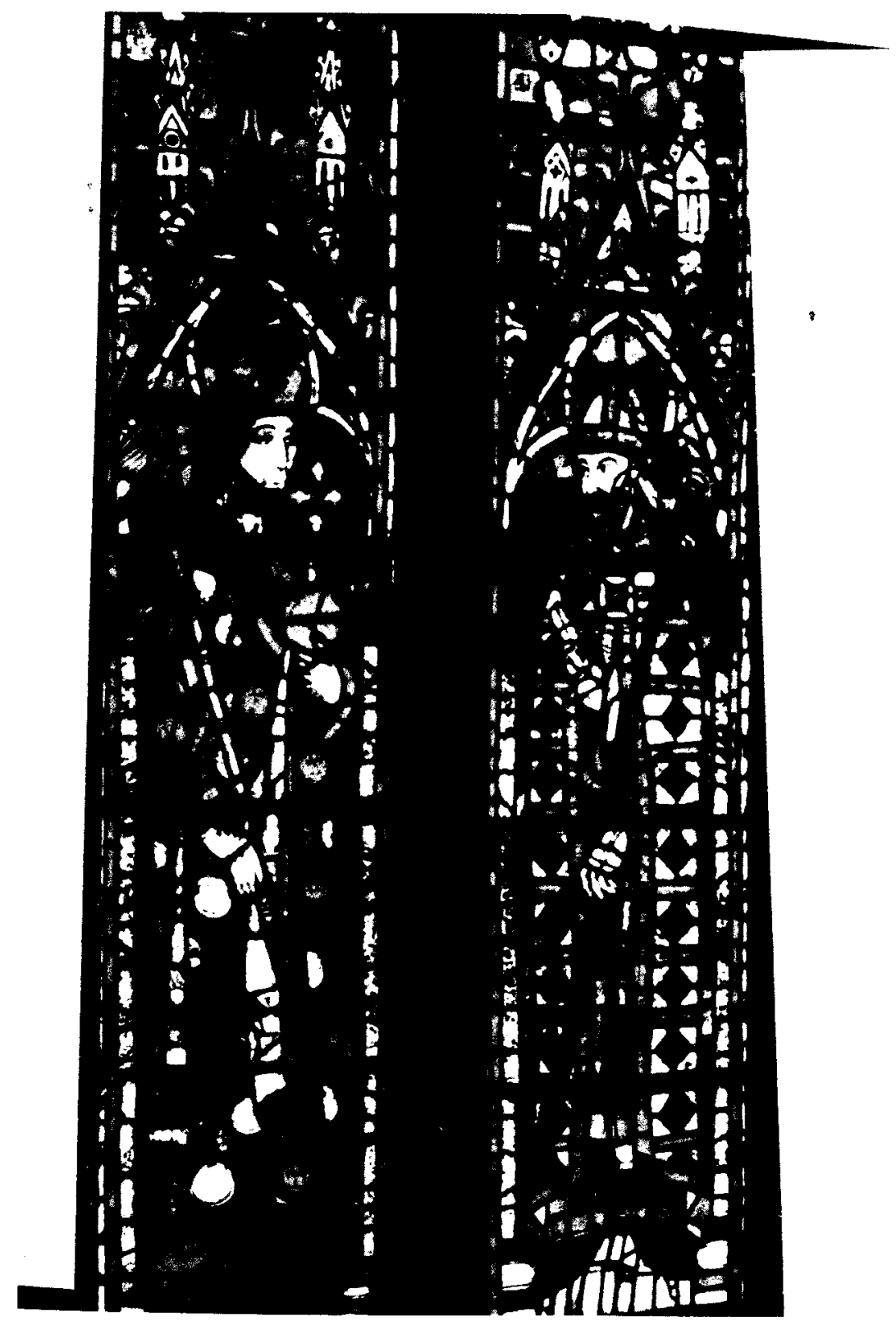

Fig. 1. Vidriera de la Catedral de León. (Alfonso X imperator) 
Circunstancias donde se revela al hombre que lucha contra las tradiciones arraigadas y que se distingue entre los demás príncipes temporales como una especie de miroir des principes. Y asi, lo mismo Las Partidas, que El Lapidario, Las Cantigas..., o La Catedral León, son la expresión del pluralismo de quien rindió culto a la cultura enciclopédica, a las summae, pero también a los símbolos de autoridad, guiado por la idea de un compromiso con un nuevo modelo de sociedad. Centro de un amplio debate cuyo principio informador era el propio afianzamiento e incuestionabilidad de su prestigio.

Catalogar, ordenar y recopilar, desde la Poética de Aristóteles, a los progresos en astronomia o fundamentos juridicos, no le llevan a «arqueologizar", sino a conferir a la tradición un contenido vivo que le prevenga y aleje definitivamente de la oscuridad mistérica de la Plena Edad Media -mundo del románico-. Por esta razón, habrá de ser su tolerancia científica quien ayude a fijar los instrumentos teóricos que demanda aquella generación "de la metafísica de la luz». A medida que la escolástica comienza a ser cuestionada, la cultura deja de ser un horizonte cerrado que se refugia en los monasterios, para encontrar en las escuelas episcopales, primero, y en las universidades, después, un sustitutivo a las viejas instituciones.

Con el incremento de la vida urbana en Castilla, había llegado la hora de superar localismos y de buscar la relación con la praxis, mientras el renacimiento aristotélico apuesta por una sociedad que haga frente a posturas ortodoxas. Y asi, al igual que en Las Partidas queda planteado el principio de autoridad real, sin las limitaciones impuestas por leyes consuetudinarias y regionales; al igual que en Las Cantigas se asume la idea del Rey como agente de elección divina que media para la realización de los milagros, en la realidad de aquella sociedad variopinta en sus componentes humanos, en la misma medida también el Rey parecería el predestinado a compaginar la cohabitación de tres culturas y tres religiones que conviven juridicamente en la legislación de Las Partidas, tal vez como "fruto de un pragmático oportunismo" (CASTRO, A.)

Es indudable que su tentativa aspira a un modelo de sociedad que relegue al ostracismo todo el viejo sistema de esquemas anacrónicos, que los avances bélicos y cambios sociales habian puesto en crisis. $Y$ mientras los límites de su tentativa dan una situación bastante compleja entre la tolerancia y la disidencia, entre el latín y la "crescenza" de las lenguas romances, se afirma un compromiso que mira esencialmente hacia la afirmación político-territorial del reino, como base ordenadora. Atrás iban quedando la intranquilidad y las incertidumbres de una guerra de Reconquista que en ciertos sectores aủn tenian valor de Cruzadas. 
Ahora corresponde al rey la tarea de llevar adelante la consolidación de su autoridad, con el apoyo de fundamentos teóricos precisos que a la vez aseguren el principio de monarquia hereditaria. Se trataba de dar fuerza al principio de realeza teocrática que, además de estar investido de rasgos sacrales, necesita de los fundamentos juridicos que sólo el derecho romano puede aportar. Quizás sorprenda menos, entonces, que las nuevas catedrales del siglo XIII, en especial las de Burgos y León, estén Ilamadas a incorporar en un plano teórico, tanto la solidaridad de los vínculos del grupo con el poder, como la afirmación del reino y la fuerza de la autoridad real.

Como contrapartida, este esfuerzo por expresar y divulgar una imagen de poder centralizadora, llegaria a chocar con los intereses de clase de un grupo nobiliario que dista de formar bloque único en torno a las apetencias reivindicativas de aquel Staufen castellano al llamado «fecho del Imperio». Hecho que, unido a una ensombrecida situación económica, puede difuminar el balance positivo del reinado de Alfonso $X$.

Para no abordar un planteamiento demasiado rectilíneo, interesará jerarquizar los problemas. Resulta imprescindible abordar el «cómo» y luego el "porqué".

En términos generales puede decirse que el perfil de la corona castellano leonesa quedaba definido por la imagen reformista de dos monarcas decisivos en la dinámica de las operaciones militares que tienen su campo de operaciones en la Andalucia Bética: Fernando III (†1252) y Alfonso $X$ ( $(1284)$. De especial interés es su impulso de un juego político que habrá de fortalecer «la inserción de la corona castellano-leonesa en el marco europeo"; sólo después de la estabilización institucional, económica y social a la que no fue ajeno el colapso del imperio almohade, afirmando en decisivas conquistas el triunfo militar de los reinos cristianos peninsulares. Por entonces la batalla de las Navas de Tolosa acababa de romper el equilibrio de fuerzas entre dos credos y desde 1212 ya era posible la apertura hacia el sur. Por encima del rápido avance de la frontera castellana, la nueva etapa quedará marcada asimismo por una peculiar situación política que será determinante: la unión definitiva de Castilla-León entre 1230-1252.

Es obvio que la incorporación de la antigua capital del califato (Córdoba) y la del sihismo almohade (Sevilia), no hará más que reforzar la jurisdicción real, afirmando el control sobre las aguas del estrecho y con él, las rutas marinas. La consolidada expansión territorial, ampliada en un cuarenta o cincuenta por ciento, dejaba atrás el desgaste de la guerra, garantizando el paso hacia una sociedad cada vez más organizada en clases y que asiste a un fortalecimiento de las fuentes de producción. La 


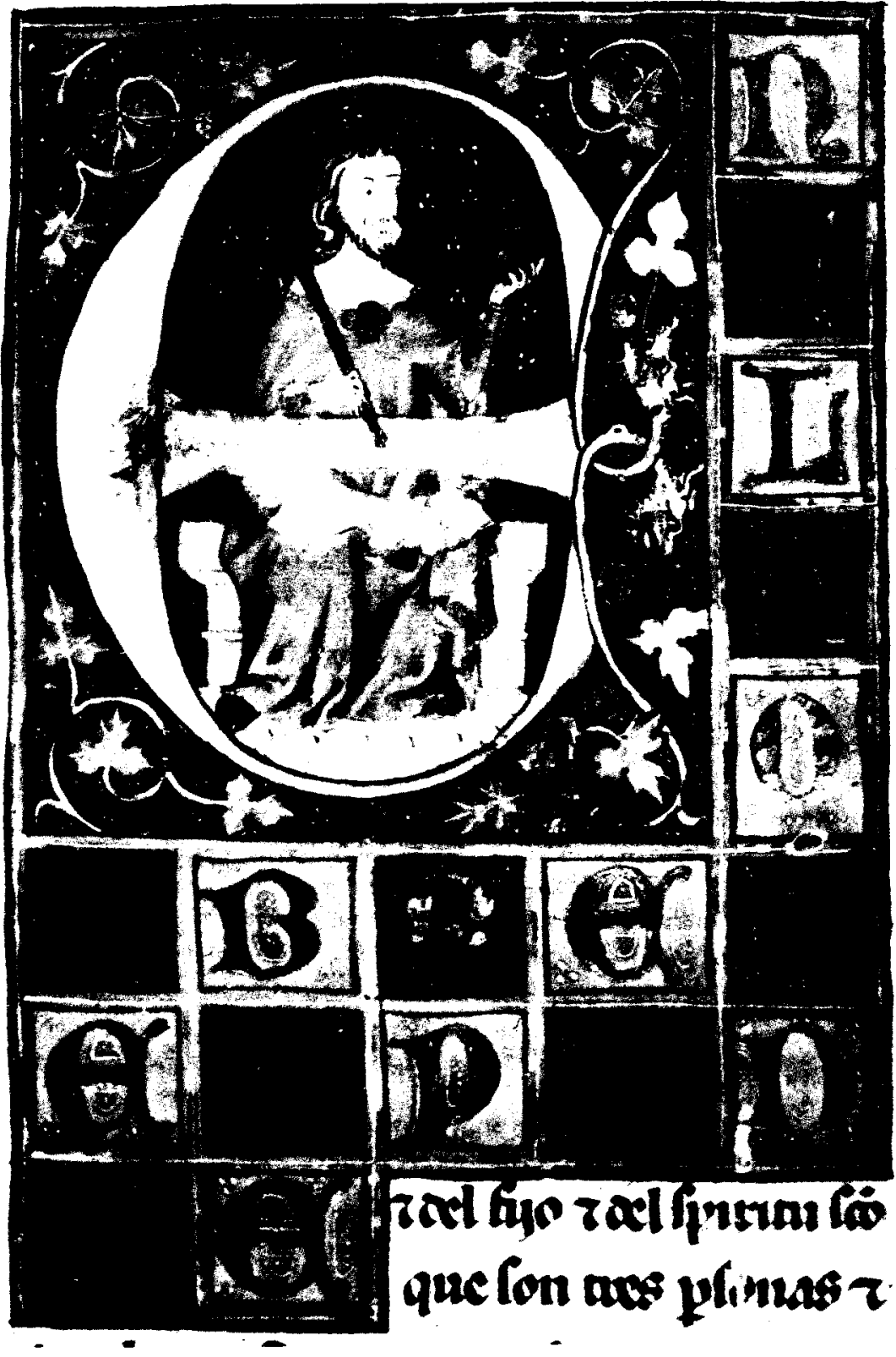

Fig. 2. Ordenamiento Real de Alcalá. (Biblioteca Nacional. Madrid) 
corona castellano-leonesa asistía al despegue de los ejes mercantiles norte-sur, mientras el llamado "camino francés" consolidaba su carácter fundamentalmente religioso. Ahora el eje de comunicación en sentido de los paralelos encuentra un fuerte competidor en el sistema viario surgido al compás de la Reconquista y que sigue la dirección de los meridianos hacia el mar y los centros fronterizos con los reductos islámicos. Estos ejes norte-sur aglutinaban tanto a centros urbanos consagrados -Burgos, Valladolid, Toledo, Cuenca-, como a los recien incorporados de la zona suroccidental del valle del Guadalquivir - Córdoba, Sevilla, Cádiz, Jerez- y Murcia - Orihuela, Lorca-, donde el éxodo norteño desde las llamadas tierras viejas conformaria la nueva realidad latifundista. A medida que los cristianos avanzan hacia el mediodia y se van tejiendo las bases de la economía castellana a lo largo de las rutas de la Mesta, el capitulo de los monasterios e iglesias románicos encuentra un sustituto en la nueva actividad edilicia vinculada a la prosperidad de los núcleos urbanos próximos a las rutas de la trashumancia. $Y$ asi, en la ruta de las mestas leonesa, segoviana y manchega, se articula una Iglesia que ayuda a perfilar la nueva realidad histórica; desde la restauración de nuevos obispados, como indicio del valor que los monarcas concedían a los eclesiásticos en la construcción de su propio reino.

Poco a poco el equipamiento de los nuevos centros urbanos se verá necesitado de un programa edilicio que organice el espacio vital, ya que su propio potencial humano asi lo demanda. Un capitulo inseparable es la catedral. Ahora bien, ésta no reduce su valor únicamente al de morada celestial donde se recrea un tipo de vida cristiana. Su panorámica es más plural. La catedral en Castilla es también el resultado de una estrecha coopresencia entre monarquia y episcopado, atenta en reforzar aquel estado que acaba de romper el equilibrio de fuerzas frente al islam, tras una especie de guerra santa. Y si la catedral era la alternativa que llede-France proponia en el siglo XIII a la Europa de las monarquias, la que realmente polarice el interés por la manera francesa habria de ser la que surja en el arranque de la cañada leonesa y defina el alma de la nueva Castilla: la catedral de León. Nos parece que esto requiere algún comentario.

Es sabido que en la promoción de la "manera francesa» en Castilla, fue de indudable valor el cometido asumido por los obispos, familiarizados con los grandes centros de actividad y foros universitarios de la época. Un reto de responsabilidad, por ejemplo, fue el asumido por el historiador y futuro arzobispo de Toledo, Rodrigo Jiménez de Rada, o Mauricio, arzobispo de Burgos; ambos muy vinculados a Fernando III. Conocedores de los foros intelectuales europeos, tuvieron la oportunidad de relacionarse con las nuevas teorias sobre el significado y valor de las 
nuevas monarquias europeas del siglo xIII, ante el descrédito de la institución imperial. $Y$ asi, ante esta grave amenaza, vigilan sobre la responsabilidad a asumir por la nueva forma de gobierno en que la soberania es ejercida en los distintos estados por una sóla persona (el rey); «pilar indiscutible de la nueva ordenación territorial en Occidente» (VALDEON) y en quien la Iglesia encuentra protección frente a los otros grupos de poder. Como la documentación hace saber, este particular cuidado por parte de la jerarquía eclesiástica, queda reforzado por su condición de colaboradores y consejeros religiosos del monarca, a la manera de Sugerio con Luis VI y Luis VII. $Y$ asi Jiménez de Rada tuvo una dilatada colaboración al lado de Fernando III, interviniendo, incluso, en la preparación de la Batalla de las Navas de Tolosa. Pero, y sobre todo, este promotor de la catedral y diócesis de Toledo -frente a las apetencias de la sede compostelana-, se definió como un teórico de la afirmación del poder real, en su Crónica del toledano (Storia gothica), donde reconoce en el pueblo godo los fundamentos de la nueva sociedad cristiana. Jiménez de Rada actuaba guiado por la idea de rescatar la perdida unidad de España.

$Y$ no se debe a la casualidad que este obispo, junto con el de Burgos, D. Mauricio, encuentre en la dialéctica del opus francigenum fórmulas generalizadoras que regulen las exigencias programáticas de las nuevas catedrales de Toledo y Burgos. Expresión aún más clara es la catedral de León; hasta entonces no se habia intentado una interpretación tan sistemática - que no mimética- de modelos franceses.

La interpretación clásica tiene presente en esta «decantación lingüística» la labor de un artesanado innovador, con «la construcción, la carpintería y el trabajo de los metales, entre las principales actividades, junto con las vidrieras", (FACl, J.). Sin embargo, las nuevas experiencias tienen mucho que ver con el carácter universal de la corte del Rey Sabio, competidor con Ricardo de Cornualles en la candidatura imperial. Sábese, asimismo, de las relaciones personales de Alfonso $X$ con la corte de los Capeto y con su rey San Luis; monarca en el que Alfonso $X$ encontrará un tímido apoyo a su oferta imperial, y con él buscará emparentar por medio de un enlace oportuno entre los hijos de ambos. Pero no basta este argumento. Por entonces muchos eran los vasallos extranjeros, sobre todo franceses, que acudían «para ser armados por el rey Alfonso $X$ » (VALDEON, J.). Todo ello alimenta la imagen de una corte que ha creado un estado de opinión fuera, lo que a su vez le exige elaborar una imagen dentro y que sea la expresión de una institución regia ideal.

Los deseos de vincularse a la práctica arquitectónica del momento, culminan en el ejemplo de León. Aqui se dan pruebas más que suficientes del clima intelectual de aquella corte y el deseo de poner en práctica un 


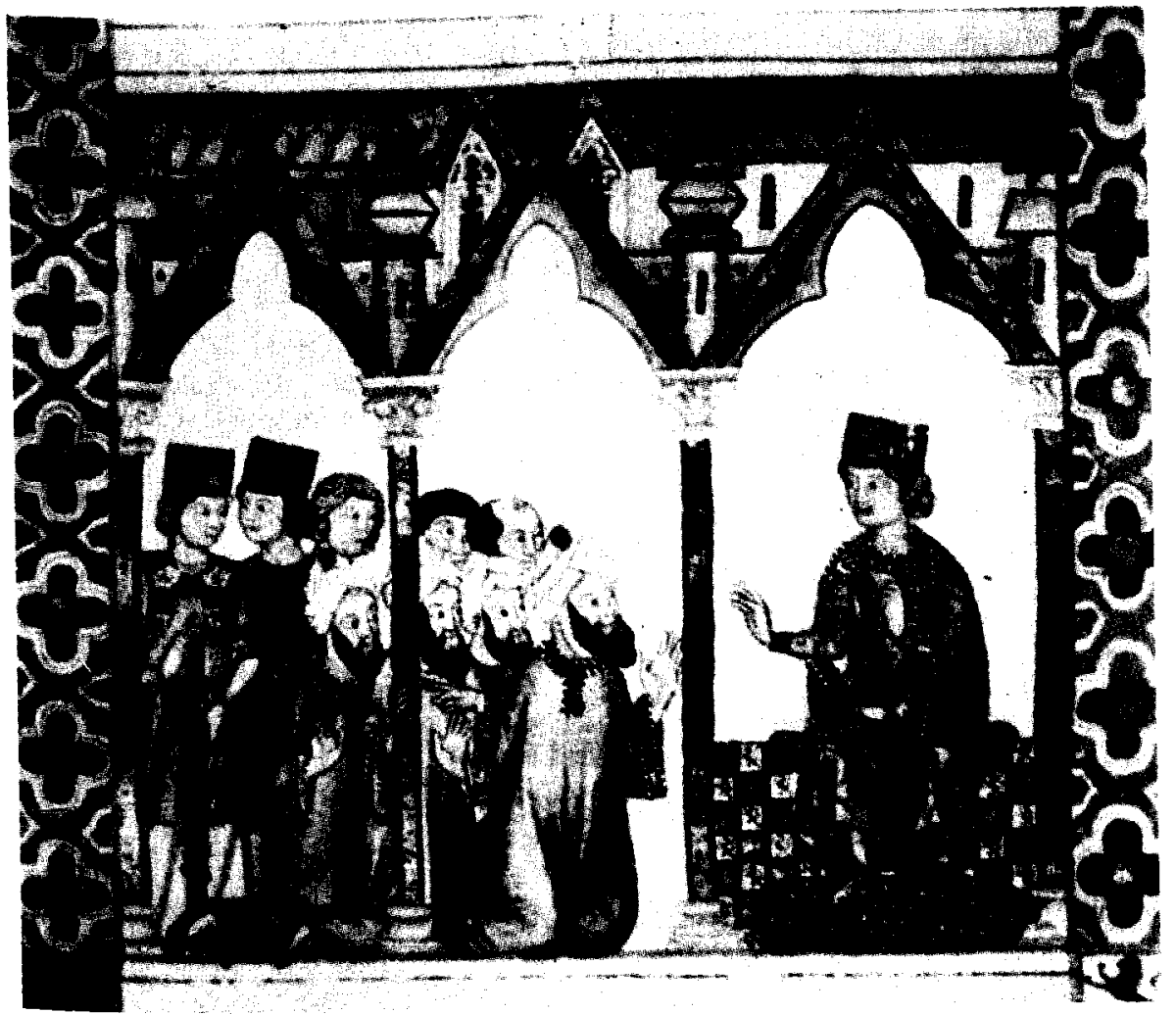

Fig. 3. La Aljama mudejar ante Alfonso X. (Cantigas de Santa Maria)

excelente referente de propaganda politica; circunstancias que impulsarian -en un primer momento- el respaldo entusiasta del rey. $Y$ es que su apoyo a los gastos de construcción, no debió de representar mucho (LINEHAN).

Las exigencias definidas en esta opus cathedralis ecclesiae no parece que hayan tenido como fin una causa única. Si por una parte era la expresión de una nueva Castilla, también hace palanca sobre los sueños imperiales del Rey Sabio. Iniciada a los pocos años de la unión definitiva de Castilla y León -entre 1230/1252-, su génesis coincide, curiosamente, con la primera oferta de los enviados de la comuna de Pisa a la corona del Sacro Imperio (1256). Estas apetencias universalistas de la corona podrian justificar el esfuerzo por legitimar los valores consagrados por los Capeto en aquellas catedrales reales que ya forman parte de la cultura internacional. $Y$ así, la nueva catedral de León, sin renunciar a su condición de simbolo espiritual — donde se reproduce la grandeza y poder 
de la imagen teocéntrica de la Iglesia como ciudad de Dios-, es también un simbolo asociado a la concepción político-religiosa de la nueva monarquia; es un simbolo asociado a la grandeza de la autoridad real, interesada en reverdecer la base jurídica que el derecho romano pueda aportar para consolidarla. Esta doble perspectiva mundana y teológica se remonta a Seldmayr, quien veía en el ejemplo leonés la afirmación de un principio histórico: era un símbolo visible del estado reafirmado tras la unión de los dos reinos de Castilla y León.

En aquella Europa que asistia a la reafirmación politica de las monarquias, Francia era el único pais capaz de ofrecer un modelo prestigiado de iglesia real y no es casualidad que León localice alli un sólido conjunto de normas generales, acordes con el nuevo modelo de iglesia ideal que ansía reproducir las estructuras del universo. Y si Reims y Saint Denis provocan un modelo catalizador cuya validez está presente en León, tal vez se deba a su valor indicativo como marco de referencia. Por una par-

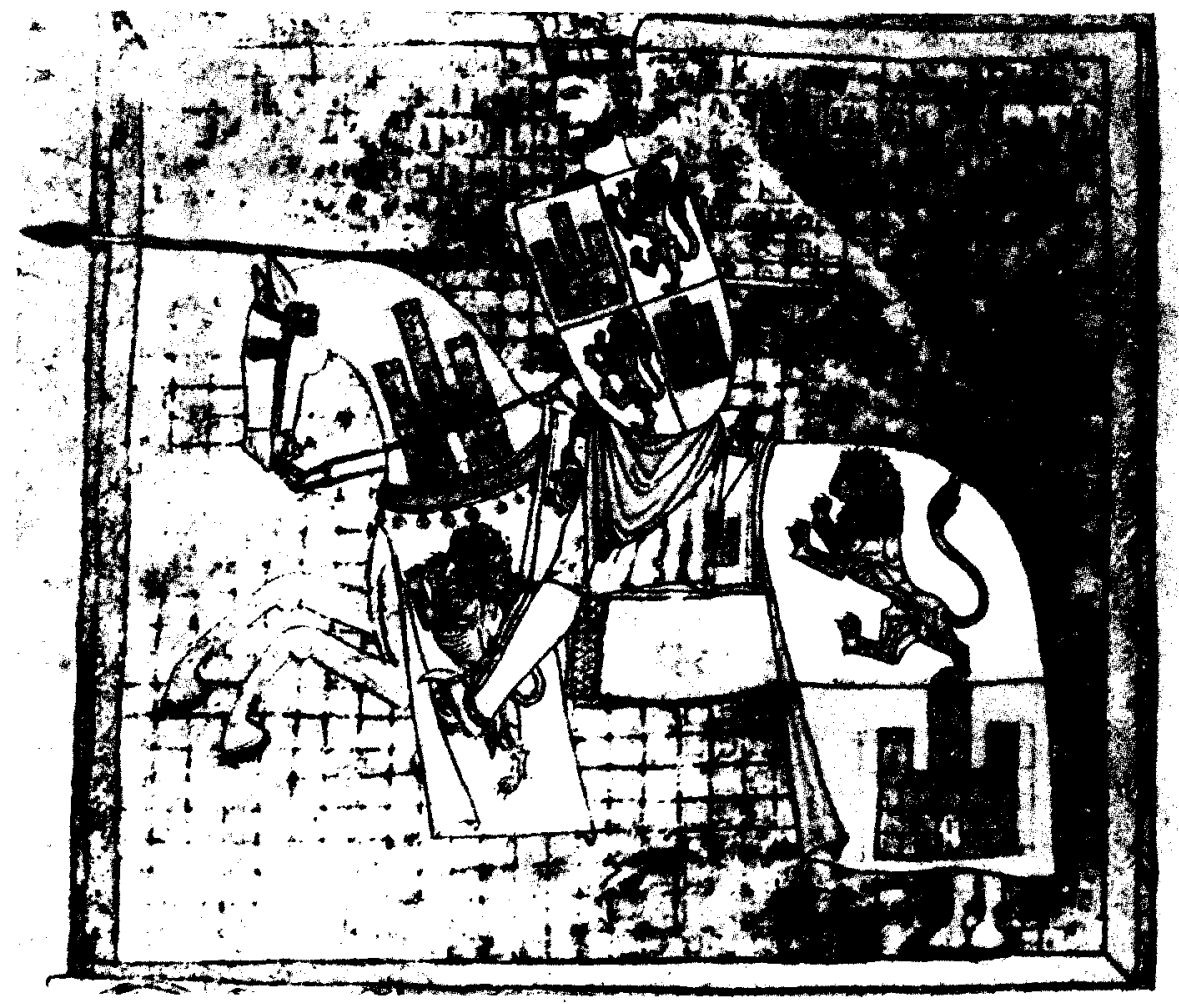

Fig. 4. Alfonso $X$ con las armas de Castilla y León. (Tumbo a Catedral de Santiago). 
te, Reims invocaba el ámbito de consagración de la monarquía de los Capeto, mientras que Saint Denis era el santuario nacional francés ligado a una idea politica: la que evocaba los fundamentos patrióticos de un reino hereditario, asi como un sentido de identidad nacional. Es un hecho verificable que el centro de consagración real en Castilla correspondia a la catedral de Toledo, sin embargo en la catedral de León se trataba de plantear el debate en su esencia; es decir, a medida que en la Castilla de la segunda mitad del siglo XIII "se afirma el carácter divino del poder real», se trata de orientar las búsquedas hacia unos referentes efectivos de valor universal: los modelos que la Francia de los Capeto ofrecia a occidente. $Y$ no parece casual que las experiencias complementarias entre si de Reims y Saint Denis, también recobren un tono parecido en la catedral que por entonces se levantaba en Colonia, como "iglesia real" (SELDMAYR), para Ricardo de Cornualles; hermano del rey de Inglaterra y rival del Rey Sabio en la candidatura al Imperio.

Este componente "ético-estético" en la «iglesia real» de León, no llevó a perder de vista las posibilidades únicamente "estéticas» de otros ejemplos franceses, como Chartres, Amiens, etc., con lo que se demuestra estar al corriente de los procesos constructivos del momento. Tales propuestas no definen a León como portavoz de una nueva teoria artistica, pero le ofrecen la ocasión para no convertirse, únicamente, en caja de resonancia de las lineas de desarrollo más significativas de aquellas "iglesias reales". León no es un espejismo que sigue, sin más, el tipo de la catedral francesa. Ello seria en arte un "signo de mediocridad" (SIMSON). León, por el contrario, dista de ser una reproducción dócil, resultando exigua su planta en cuanto se la relaciona con su altura, a la que supera únicamente Beauvais (Gomez MORENo). Este podria ser ese celemento de rebelión" que Simson, acertadamente, entendía como el rasgo a considerar en una obra de arte. Es verdad que su sistema arquitectónico no es nuevo, pese a ello, no se trata de insistir en lo que pueda tener de reflejo de toda una serie de influencias, aunque esta condición adquiera preferencia en el enfoque de determinada bibliografia. Se trata de considerar los términos que entran en la génesis de la Catedral de León, al objeto de evitar una imagen confusa que puede derivar hacia la desarmonia; o, lo que es igual, a proclamar una imagen ficticia, cuando en realidad dicha catedral está estructurada y ordenada en torno a unas motivaciones reales que son históricas y universales. $Y$ lo que es universal, como se dice en historia del arte, conduce a lá armonia.

Quiza habria de poner mayor énfasis en lo que representa aquel momento para el afianzamiento de la monarquia castellano-leonesa, tras la consolidación territorial y, simultáneamente, el deseo de reforzar los fun- 
damentos teóricos del poder real. Es por esto que el análisis de la catedral de León obliga a resaltar dos aspectos que son algo más que dos fórmulas retóricas: "el sistema de simbolos asimilables a la idea de poder» y el respeto al "locus histórico" sobre el que habria de surgir la filosofia del nuevo edificio, símbolo de una conciencia protonacionalista.

a) Sistema de símbolos asociados a la idea de poder. Decia Norberg Schulz que así como en la arquitectura románica se crean los referentes necesarios para que el hombre reciba a Dios, es en la catedral gótica donde Dios se acerca al hombre. La nueva catedral pretende hacernos ver un espejo del mundo y su acción ordenadora se apura a demostrar como racionales las verdades adquiridas. De igual modo, junto al programa iconográfico de los personajes de la Historia Sagrada, adquiere protagonismo propio la figura del rey. Un rey al que se considera elegido para ejercer un poder delegado por Dios. Y asi, en el ordenado cosmos cristiano creado en las vidrieras de la catedral leonesa - hoy muy poco esclarecedor, por la reacomodación de aquellas-, al lado de Alfonso $X$ se sitúa al hombre coparticipe en la elaboración de aquel edificio: el obispo Martín Fernando. Y aunque la vidriera del segundo está muy retocada y acumula la duda de otra anterior, la conclusión lógica es que ambas imágenes sugieren los dos ordines no subordinables de aquella christianitas: el del regnum y el del sacerdotium, el temporal y el espiritual en la mejor tradición legislativa del momento y conforme a ese criterio de los dos poderes vuelto a reproducir en la escena de la celebración de los oficios religiosos de Las Cantigas. Si se hecha mano de una base teórica en el Speculum de la Biblioteca Nacional de Madrid, citado por Macdonald, se proclama la suprema autoridad del rey: "spiritualmente dezimos que el rrey es alma del pueblo... naturalmente el rrey es cabeça de su rreyno" (2:6.2); por su parte Las Partidas aún van más allá al reconocer al rey como "puesto en la tierra en lugar de Dios" (II,I,V.).

Si la época asumía que monarquia y episcopado eran de origen divino, ello suponía que deberían hacer "causa común en relación a múltiples asuntos" (NIETO SORIA). Especificando más, se comprende que la catedral leonesa sea la expresión de una alianza armónica que, en este caso, habria de concluir con el exilio de aquel prelado en 1279 , tras un enfrentamiento con el rey.

En nuestra opinión, al igual que en Francia la iglesia real exalta la posición de supremacia de su monarca, León transmite una posición similar: aquel locus sin dejar de ser una iglesia episcopal, no elude su condición de iglesia real. Las vidrieras citadas no hacen más que enfatizar en dicha propuesta; al margen de ese valor propagandístico, sobre el que volveremos, donde se reivindica la superioridad del poder real. 


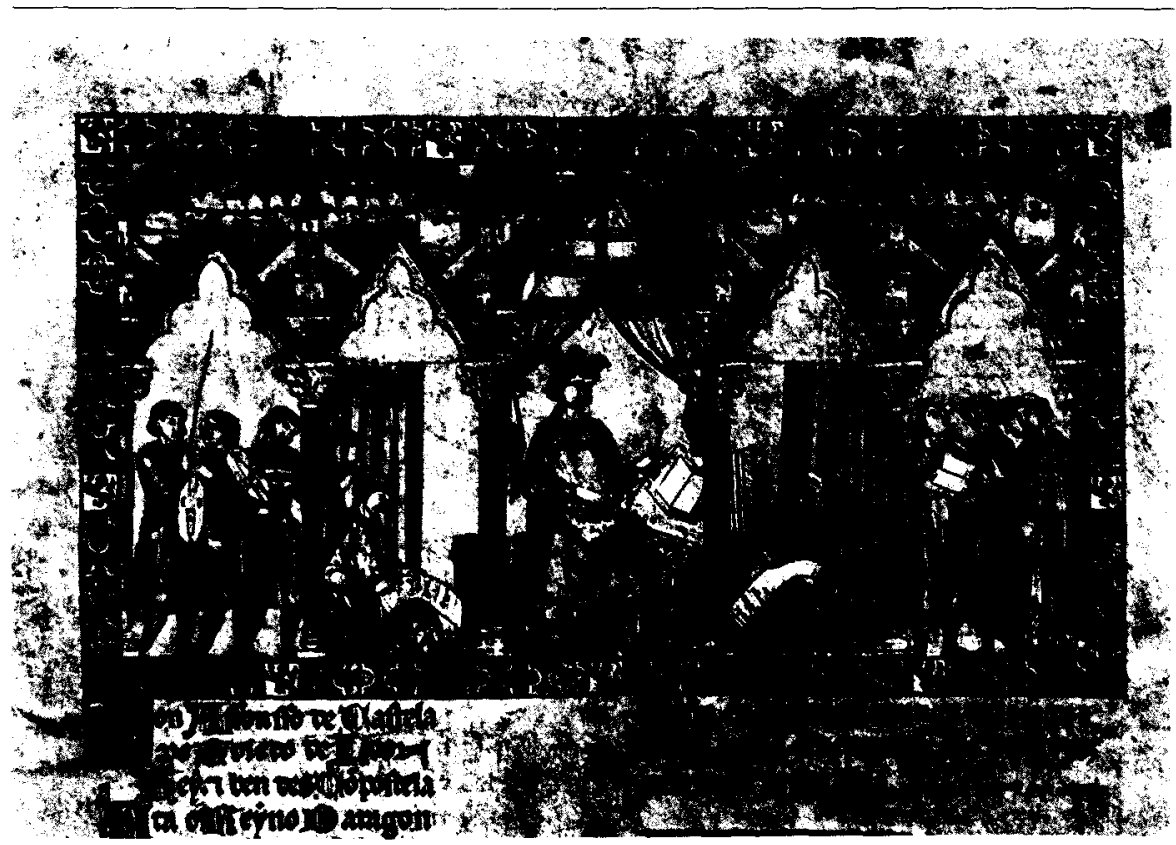

Fig. 5. Alfonso $X$, trovador

Es una etapa en que las ciudades muestran una irrefrenable inclinación hacia lo bello, el refinamiento de la catedral, además de ser un signo visible de la autoridad del episcopado y de la monarquia, también reproduce el modelo de aquella sociedad medieval; lo que equivale a decir que va más allá de su condición de ámbito de oración: la catedral era también ámbito de justicia. Si se tiene en cuenta que uno de los objetivos de la corona era la administración de justicia, resulta significativo el valor concedido al llamado locus apellationis, en el nártex de aquella iglesia real. Como corresponde a una monarquia que basa la relación con el súbdito conforme a un sistema legal y donde el rey, como vicario de Dios y a imitación suya, debe adoptar un proceder lícito, el locus apellationis se identifica con esa imagen del rey expresada en el Speculum y donde se dice que deberá hacer justicia en su reino, en los aspectos temporales (2:15.1). En este capítulo de administración de justicia, el rey estaba ayudado por la curia regis. $Y$ puesto que eran muchas las apelaciones a la curia, en el ámbito local era ejercida por cuatro jueces -en representación del rey, iglesia, nobleza y pueblo-, celebrando los juicios de apelación o alzada conforme al Fuero Real -el empleado para imponer la uniformidad en casos de apelación-y tal vez en concurrencia con el Fuero de León. Este poner orden en el cielo y en la tierra aseguraba el equilibrio ideal de la civitas Dei en la tierra, donde el rey era la autoridad 
legislativa absoluta. Pero conviene no olvidar la tradición fijada desde el siglo $x \mid$ en León, en lo que se refiere a los reyes como encargados de promulgar leyes en concordancia con la curia como órgano de consulta (MACKAY).

b) El respeto al locus histórico. Si hubiera que fijar una metáfora, la catedral de León no sólo se revelaba como expresión sensible del poder, sino también como «instrumento nacionalizante, al servicio del poder politico" (CORTAZAR); circunstancia puesta de relieve por los historiadorescronistas de la época, cada vez más sensibilizados ante una vuelta a la unidad preislámica, tomando el hilo conductor de sus argumentos desde los antiguos reyes visigodos. En otras palabras, se trataba de buscar el origen de una monarquia histórica que a la vez de sentido a un despertar al sentimiento de identidad nacional; tal como se evoca en la Crónica General del Rey Sabio al reemplantear el "loor de España", siempre vivo, "como una imagen de grandezas pasadas que los reyes leoneses y castellanos aspiraban a restaurar" (CASTRO, A.).

En aquel despertar de las monarquias históricas en Europa, tal vez convenga recordar que tal añoranza por un pasado ilustre también fuera puesta de relieve por los Capeto, desde que Sugerio buscara en la abadia real de Saint Denis las intenciones nacionalistas de la casa real: Saint Denis era un antiguo locus sacro de tiempos altomedievales, surgido a la sombra histórica de Carlomagno y donde éste construyera o completara el sepulcro de su padre, Pipino el Breve. En realidad, los Capeto y su teórico Sugerio, estaban buscando la legitimidad que pudiera proporcionarle la herencia del emperador Carlomagno y con ella la afirmación de una identidad nacional.

En cuanto a la catedral de León, ¿cuáles eran las pruebas objetivas de su dimensión histórica? Para Alfonso X, monarca con pretensiones internacionales y que aún en 1260 no dudaba en llevar al norte de África "el fecho de la Cruzada" (VALDEON), León era el emblema de la reciente unidad politica, pero también el locus que le permite ordenar su pasado; en otros términos, le proporcionaba la legitimidad de los antiguos reyes. Esta continuidad con el pasado histórico pone de manifiesto un significado amplio: acentuar la asociación de la casa real castellana con la linea leonesa; unión que intentara evitar en el pasado Alfonso IX de León.

¿Cómo se expresa la continuidad con aquel pasado histórico? La nueva catedral quedaba cimentada sobre una reconstrucción de la segunda mitad del siglo xI. Ésta, a su vez, sepultaba el "aula regia" de Ordoño II $y$ el enterramiento de este monarca que habia integrado en una unidad política al territorio astur-leonés. Y puesto que el proceso de creación de una conciencia nacional en la Peninsula lbérica se remontaba a los tiem- 


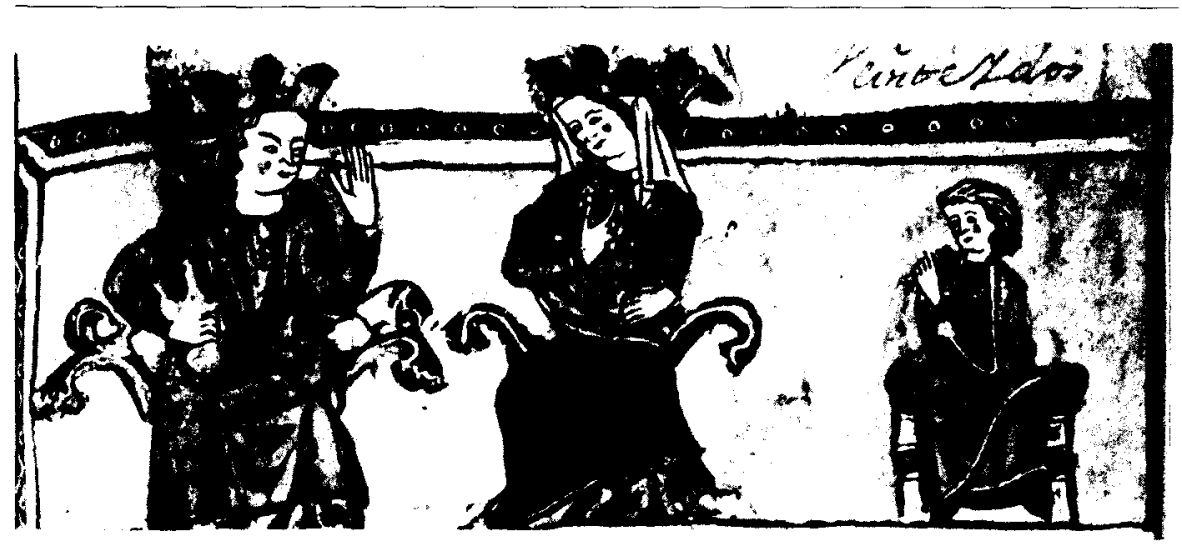

Fig. 6. Alfonso X. Doña Violante y el Infante de la Cerda.

pos visigodos, se impone tener en cuenta que Ordoño \| -quien había convertido a León en centro político de su reino asumiendo la dirección de la politica cristiana frente al Islam - habia propiciado el "revival" de aquel pasado glorioso desde una afirmación del ideal neogótico, como hiciera Oviedo en el siglo anterior. Pero habia algo más: la fuerza expresiva de una idea nacional, habia llevado a Ordoño II a autoproclamarse Imperator legionense —como le denominará más tarde la Crónica Najerense-.

Pero no fue Ordoño II el único monarca que podría proporcionarle la legitimidad imperial de los antiguos reyes leoneses; una valoración históricamente correcta de aquella ciudad resulta inseparable del recuerdo de Alfonso VII y de su coronación imperial en el 1135; monarca que, además de ser un reto de referencia contínua cuyo modelo pretendería aplicar Alfonxo X (MACDONALD), justifica un referente próximo de la institución imperial peninsular. Todos estos precedentes legales dotarian a la ciudad de una especial posición de preeminencia, llegado el momento de institucionalizar un concepto que situaria a la realeza castellana en una especial posición en el occidente.

Ante el prestigio de la ciudad y el preciso concepto de autoridad universal de la realeza leonesa, la nueva catedral ofrece una incomparable ocasión para conferir cierta oficialidad al recuerdo de Alfonso el Sabio como imperator; punto que se ajusta a unos propósitos políticos incumplidos, pero muy en consonancia con la imagen de superioridad que dicho monarca ansiaba proyectar de si mismo y que dogmatiza en el Speculum al sublimar su posición: "non avemos mayor sobre nos en lo temporal». $Y$ a tono con tal imagen de la más amplia autoridad deberán estar toda una serie de cualidades personales que justifiquen tal preeminencia ab- 
soluta; viejo lema que se ha invocado de manera continua a lo largo de la historia y que sitúa a la propia arquitectura como un medio efectivo que se convierte en vestigio simbólico de autoridad tan importante como pueda ser el propio interés por «las ciencias e saberes». Exigencias programáticas de supremacia que, en su caso, además de etiquetar el cosmopolitismo de una vocación, centran su atención en el deseo de expresar el esplendor de una politica propia atenta al concepto y a la praxis.

No es éste el lugar adecuado para plantear la problemática de las catedrales de Burgos, Toledo y León. Digamos sólo, para centrar nuestro objetivo, que están asistidas por una corona que busca transmitir la imagen de monarquia fuerte y hereditaria, como expresión de un mensaje dirigido a fortalecer el aparato del estado. Y no esto sólo. Cada una de ellas parece depositaria de una tradición.

La catedral de Toledo era el nexo con las raices; es decir, estaba asociada con el centro religioso e institucional de época visigoda, cuyos concilios sentaron las bases de la nación española. Si bien la corte residia temporalmente en Sevilla, Segovia o Burgos, Toledo era considerada capital de facto donde los monarcas habrian de fijar su necrópolis. En cuanto a León, además de cuanto se lleva dicho, mantenia la tradición de ser un ámbito celebrativo de asambleas representativas, siendo las cortes alli celebradas en 1183, las primeras documentadas (MACKAY), con asistencia del rey, la nobleza y la jerarquia eclesiástica.

La archidiócesis burgalesa, por el contrario, estaba ligada a su función mercantil y su catedral centralizada la vida religiosa y económica. Parada obligada en la ruta a Compostela y epicentro para el tráfico maritimo, era el centro urbano más activo de Castilla. Pero hay algo más. Cuando se realizó el programa iconográfico que da la vuelta a las torres de su catedral, se valoró decisivo el rememorar en aquel marco sacro una genealogía elaborada sobre los cimientos del pasado: desde Fernando I, rey de Castilla y León a los hijos del Rey Sabio, como glorificación de la dinastía castellana, afirmada en su identidad nacional. Esta interesante observación de Cómez Ramos y Franco Mata, me permite reforzar la teoría sobre el valor a recuperar en Burgos. Es decir, Toledo, como después León, tratan de profundizar en unas supuestas o reales raices históricas. En cuanto a Burgos, tan vinculada a los esponsales reales desde antiguo, habrá de ser quien recoja una iconografía sobre la crónica histórica de aquella monarquia castellano-leonesa. Propone un providencialismo ordenador y legitimista que cierra filas en torno a Alfonso $X$, como portavoz carismático de una función querida a Dios, solidario con su genealogia, garante del orden e imagen de un sistema de poder. 
Estas tres catedrales del siglo xill, por consiguiente, ayudaban a remarcar la evidencia de una realidad politica y la fuerza de la autoridad real. Una realeza que goza del privilegio de ser ungida con óleo consagrado, como lo habian sido en el pasado los monarcas visigodos, y que para legitimar la pretensión de su supremacia sobre otros reinos cristianos, busca su justificación en la Iglesia y en los vínculos históricos del primer reino cristiano-visigodo y del reino "astur-leonés-castellano", como gustaba decir a Alfonso X en su Primera Crónica General.

Por si todavia quedaran dudas, aquel monarca que estaba construyendo el edificio estatal, también aspiraba a la corona del Imperio. $Y$ aunque esta búsqueda llevara a suponer para determinada bibliografía un viaje imaginario, tal vez por el propio descrédito de la institución imperial, todavia era la manifestación de la primacia europea.

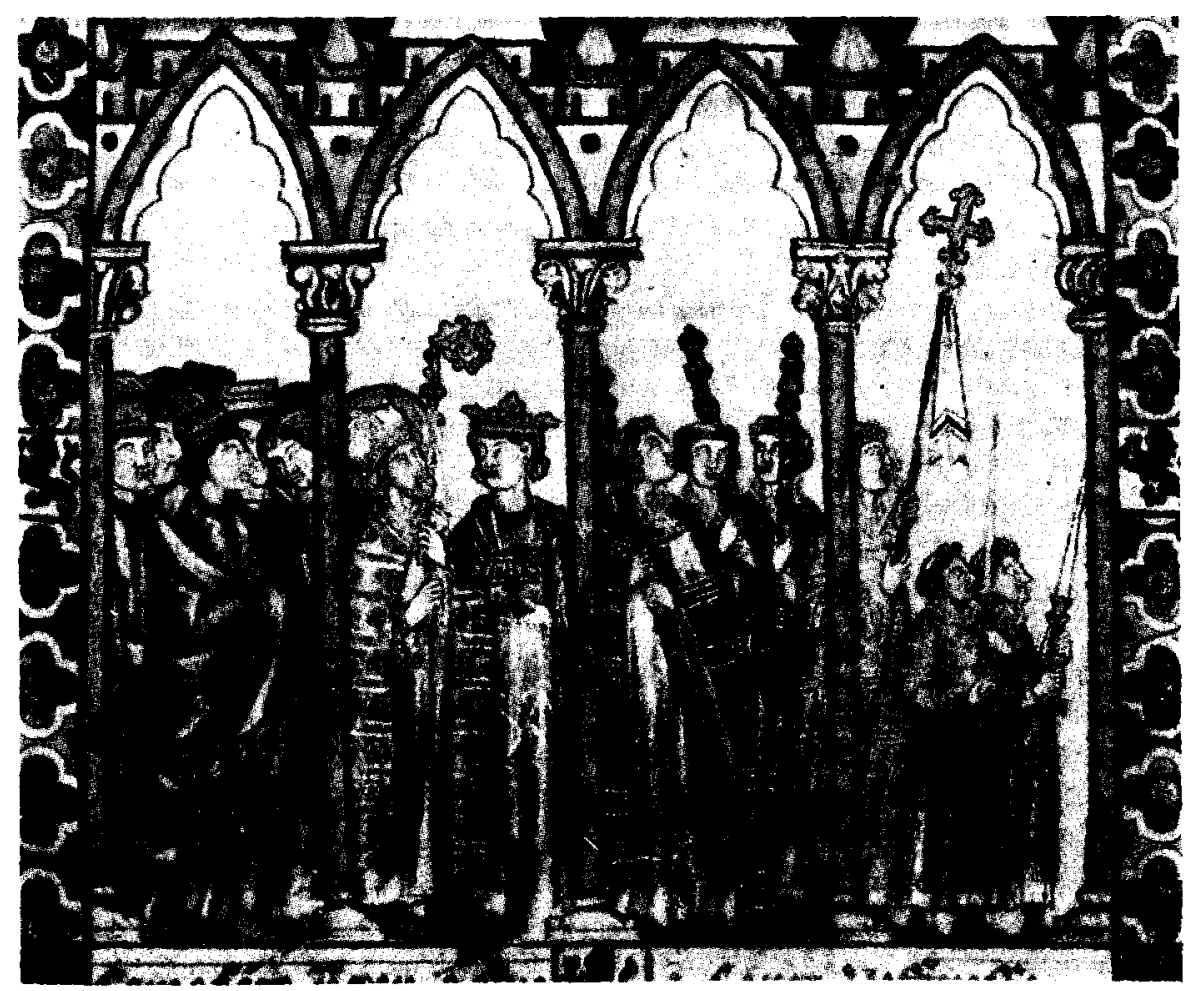

Fig. 7. Alfonso $X$ cumpliendo con un ritual lutürgico. 


\section{ICONOGRAFIA RELACIONADA CON EL "FECHO DEL IMPERIO"}

Desde el punto de vista de la iconografia, las múltiples imágenes de Alfonso $X$ experimentan un tableau vivant de teorización $y$ experimentación ejemplar sobre el «rey justo" que sabe rodearse de consejeros idóneos (Libro de Ajedrez); el "rey sabio" que atiende a comprender tanto el mundo del cosmos como la realidad del buen gobierno (Cantigas de Santa María) para complementarse con la del "rey guerrero" (Tumbo. Catedral de Santiago). Estos aspectos, reveladores de una imagen de poder prestigiado, parecen quedar ampliados con la exaltación de su maiestas y auctoritas, en la mejor linea de una función imperial; delicado problema que pone el acento en su preponderancia emblemática, conforme a la voluntad divina.

Nunca, como hasta ese momento, la imagen del poder real había afirmado una visión del soberano entre la realidad y el componente mítico. Más allá de una visión tradicional, su iconografía materializa al nuevo príncipe: ambicioso en sus objetivos, actor y juez de una aventura propia en la que no reconoce superiores; era esa imagen que ya a comienzos del siglo XIII, como recuerda Nieto Soria, defendia Vicente Hispano al subrayar los méritos y esfuerzos de aquellos reyes atentos a recuperar las tierras que la cristiandad habia perdido ante el Islam; labor que entreve en la conceptualización del monarca una superioridad regia que le califica de «verdadero emperador". De hecho, sus proyectos de reforma legal, reorganización del sistema administrativo, participación personal en las letras, el arte y el estudio, no hacen más que traducir la imagen del rey perfecto, cuya poliédrica actividad programática queda asociada a la actividad politica, científica, literaria, artística y jurídica. Quizá deberia de decir que tales eran las intenciones del capitulo de El libro de las taulas alfonsies, donde se enfatizaba «El señor rey, Alfonso, aventajaba en sabiduría, inteligencia, prudencia, ley, bondad, piedad y nobleza a todos los demás reyes sabios del mundo». Discurso que estructura y ordena el saber y la clarividencia práctica de quien era reconocido como «escodriñador de ciencias, requeridor de doctrinas e de enseñamientos que ama e llega assi a los sabios e los que entremeten de saberse e les face algo e mercet» (DIEZ dE REVENGA). Sin duda, los múltiples cometidos del rey y su filosofia del poder, traen al recuerdo aquel modelo positivo de Tomás de Aquino - retomado por Claudette Perrus- que poseía valor de descubrimiento copernicano: "rois, qui sont nombreux, et les bons son rares".

Las Cantigas parecen destinadas a subrayar un aspecto ejemplar del poder. En ellas se ratifica la función del rey justo y trovador de María, en su convicción de elegido por la divinidad como mediador en el milagro, 
para mantener el orden social conforme a una ética. Una función arbitral de otro tipo es la recogida en el Tumbo de Toxos Outos; en este caso el valor de ciertos atributos - la corona, espada, manto de púrpura y tronoevidencian la simbología real, donde derecho natural y derecho divino se dan la mano. Junto a esto, la presencia del Infante de la Cerda, ayuda a consignar la personalidad juridica del primogénito. Se trataba del heredero de Castilla, Toledo, León, Galicia, Sevilla, Córdoba, Jaen y el Algarbe, conforme a las disposiciones recogidas en Las Partidas, pero también del sucesor en el Imperio al que los marselleses prometieron servir (WOLF, A.).

En los «alicatados murcianos» se aprecia al hombre politico que debió de acometer en 1266 una acción militar - no exenta de un cierto espiritu de cruzada - ante la situación creada por los musulmanes del reino vasallo de Murcia en 1264. En cuanto a la iconografia real recogida en la propia catedral de Burgos, queda unida a la importancia acordada a la exaltación de aquel linaje histórico, como particularmente elegido por Dios, y conforme al carácter hereditario de un reino que consolida sU aUtoridad: “Nos que avemos el rregno por derecho heredamjento" (SpecuIum 1:1.13).

En contraste con esta garantia de legitimidad del linaje real, la «vidriera de la Catedral de León» se encuentra vinculada a la personalidad política de aquel monarca ambicioso en sus objetivos, añadiendo un explicit a su curriculum.

Se trata de una vidriera en la que Gómez Moreno, Nieto Alcaide, Cómez Ramos y González Arenas creen reconocer a Alfonso X como dignidad imperial. Como ha demostrado nuestro análisis, todo apunta en ese sentido. Representa un ejemplo particularmente llamativo y de valor inestimable, con una data razonable a los años anteriores a 1275. ¿Qué razones podrian invocarse?

Desde el punto de vista histórico, no parece probable que esta vidriera real ocupara originariamente el emplazamiento actual en el lado norte de la nave central. Se hace imprescindible recordar que a lo largo del tiempo las vidrieras de esta catedral sufrieron cambios y arreglos, siendo desmontadas casi en su totalidad en el siglo XIX, e incluso antes.

Si en rigor las más antiguas se emplazaban en las capillas absidiales, esta relación deja bastante claro que la correspondiente a Alfonso $X$ tuviera una localización preferente en las proximidades del ábside principal; cuando por entonces la politica exterior de aquel monarca intuia mayores posibilidades en el llamado "fecho del Imperio". Lejos de plantear un debate sobre el valor de estas aspiraciones, la historia reciente examina con mayor detenimiento su posición y esfuerzos por lograr aquel 


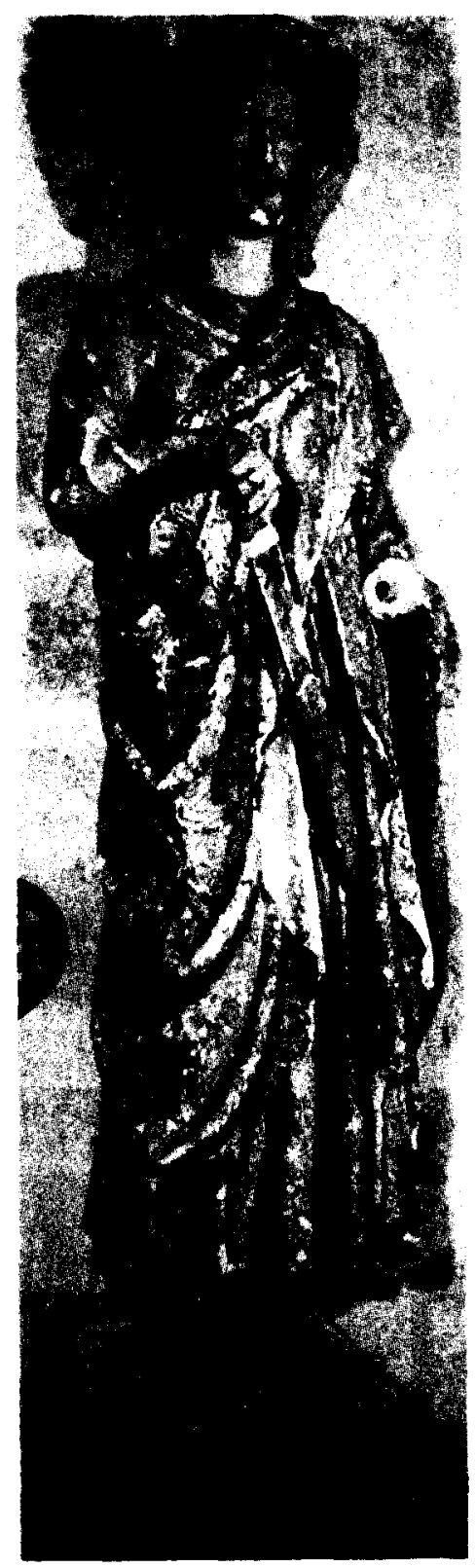

Fig. 8. Ordoño II. 
vestigio simbólico de autoridad durante los años comprendidos entre 1259-1275; fecha en que habrá de producirse una "relativa renuncia a la oferta imperial" (EstePA). Para entonces el llamado Maestro Martín (†1277) habría cumplido el trazado fundamental de la cabecera de la catedral leonesa, viéndose rematada en lo esencial a los diecinueve años de la muerte de Alfonso X (†1284), en 1303. Por ello, no parece que tenga mucho sentido elaborar una vidriera de su maiestas en los comienzos del siglo XIV, a modo de devoto homenaje. Empresa que, además, no parece haber entusiasmado, ni a la nobleza, ni al pueblo castellano, suscitando reacciones adversas.

Por añadidura, si se considera que Alfonso $X$ nunca contó con la sanción pontificia como rey de romanos, ¿cuál es la base real de esta iconografia? Si se establece una comparación con la actitud observada por el otro aspirante al Sacro Imperio, Ricardo de Cornualles, no hay duda que éste observaba idénticos propósitos. Conforme a la indicación de Seldmayr, Ricardo de Cornualles también se ocuparía en la fijación de símbolos de dominio; en particular, tras aumentar el tesoro real de Aquisgrán con "la corona, el cetro, la bola del mundo y costosos trajes", recurrió a su representación en la curia de Aquisgrán rodeado del collegium de los siete principes electores.

En cualquier caso, la empresa contaba con precedentes y Alfonso $X$, que casi consigue la ilusión de verse coronado emperador, también prevee la posibilidad de apelar al valor de ciertos atributos que definen tal condición: la bola del universo en la mano izquierda y el cetro con el águila imperial a la derecha, atributos diferentes a los que porta en el Tumbo de Tokos-Outos y más en la línea de los que se distinguen en la miniatura del ordinamiento de Alcalá (B. N. Madrid). Ambos casos dan sentido y valor a unas posturas celebradas al mismo tiempo: mientras Ricardo de Cornualles "habia sido elegido en un lugar ilegitimo, en las afueras de Franckfort", Alfonso X "es elegido emperador de los romanos por Pisa y Marsella" dentro de la ciudad electoral de Franckfort, si bien tal elección no llegaria a consumarse hasta el 1 de abril de 1257, ante la presencia de los obispos de Spira y Worms; conforme a las noticias transcritas del Regesta imperii por Armin Wolf, quien insiste en que fueron dos elecciones concurrentes y no una doble elección.

Ante este dato, sorprende que cierta bibliografía insista en que esta aspiración del rey Alfonso queda bastante al margen de la realidad del momento. Acaso se imponga recordar que en el año 1262, en plena génesis de la Catedral de León, el papa Urbano IV no dudara en dirigirse al rey "empleando la titulación de Rey de Romanos» (EsTEPA). Por entonces, aunque esta aspiración no había alcanzado una sólida aclamación 
en Castilla, eran los gibelinos de Pisa quienes libraban una batalla teórica que todavia en 1270 le reconocia como Rey de Romanos, autodenominándose en 1271 Dei gratia Romanorum semper augustus; título que no desestimaba en el 1281, pese a los desalientos del Papa.

Sostenía Simson que en el pensamiento medieval un simbolo para ser aceptado "tiene que ser una imagen convincente de la realidad que debe representar». Debemos preguntarnos, entonces, cuál podría ser el alcance de este simbolo de sus proyectos. Aunque las demandas imperiales de Alfonso $X$ acaban difuminándose, entiendo que este símbolo de la autoridad secular universal refunde dos tesis; dos fundamentos presentes en la vida politica de aquel rey comprometido, asimismo, con la afirmación de una identidad nacional.

1. Si se admite como válida la información de Jofré de Loaysa, el referente plástico de esta vidriera podria fijar la imagen de quien fuera proclamado rex romanorum (Rey de Alemania) por cuatro de los siete principes electores, si bien no llega a acceder a la dignidad imperial del Sacro Imperio. Tal vez se deba a esta circunstancia que su imagen carezca del nimbo que declara la realidad última de la gracia divina; o, lo que es igual, queda desprovista de la importancia que la iconografía del emperador suele acordar a su función glorificadora, a la realidad sacralizadora que le transcienda. Elemento, por la demás, particularmente presente en las imágenes imperiales de la Catedral de Strasburgo, lo mismo las referidas a Carlomagno, como las vidrieras del siglo xIII donde queda representado el rey Conrado con el futuro Enrique III.

2. Además de sus pretensiones al Sacro Imperio, no debe pasarse por alto otro valor adicional: «Alfonso era muy consciente de la institución imperial peninsular, por muy efímera que pueda parecer a los historiadores modernos" (MACDONALD). Ciertamente, algunos textos del Espéculo recogidos por este autor, mantienen viva esta sensibilidad cuando evocan a un monarca convencido de la superioridad de sus responsabilidades y que declara que "non avemos mayor ssobre Nos en lo temporal» (Especulo 1:1-3).

En cualquier valoración no puede dejarse de lado que este criterio centra su atención en unos anhelos de autoridad que aporten las mayores ventajas para Castilla. Ello le orienta a renovar, como descendiente que era del emperador Alfonso VII de León, las pretensiones imperiales leonesas, "pese a que Jaime de Aragón recelaba de ello" (MACDONALD). Se trataba de unas reivindicaciones que Fernando III habia rechazado, como proyecto demasiado precoz, y que Alfonso $X$ deseaba volver a instituir, ahora que tenía como tributarios a los mandatarios islámicos y era cabeza de la monarquia dominante en la Peninsula. Por otra parte, esta as- 


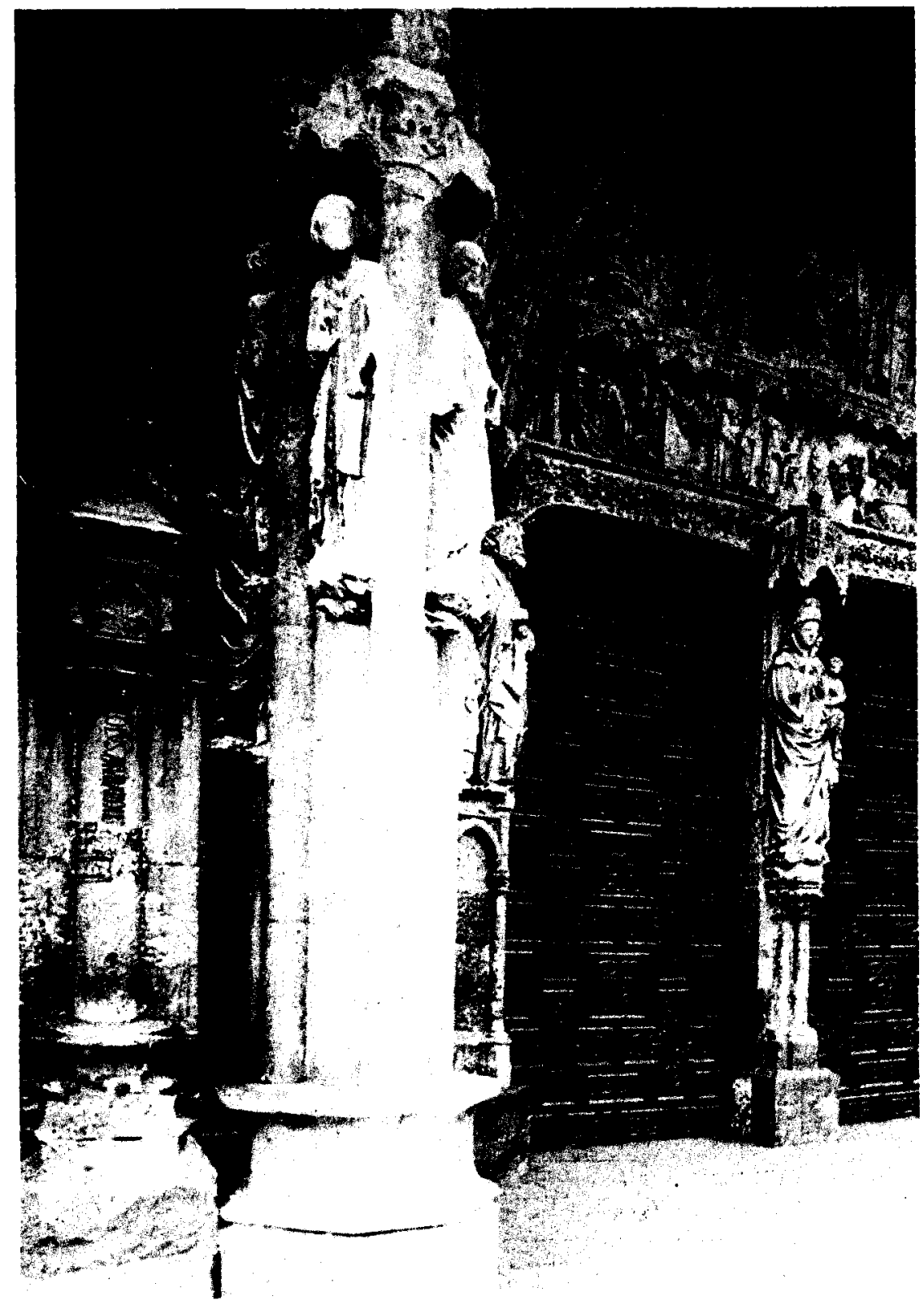

Fig. 9. Locus apellationis. (Catedral de León). 


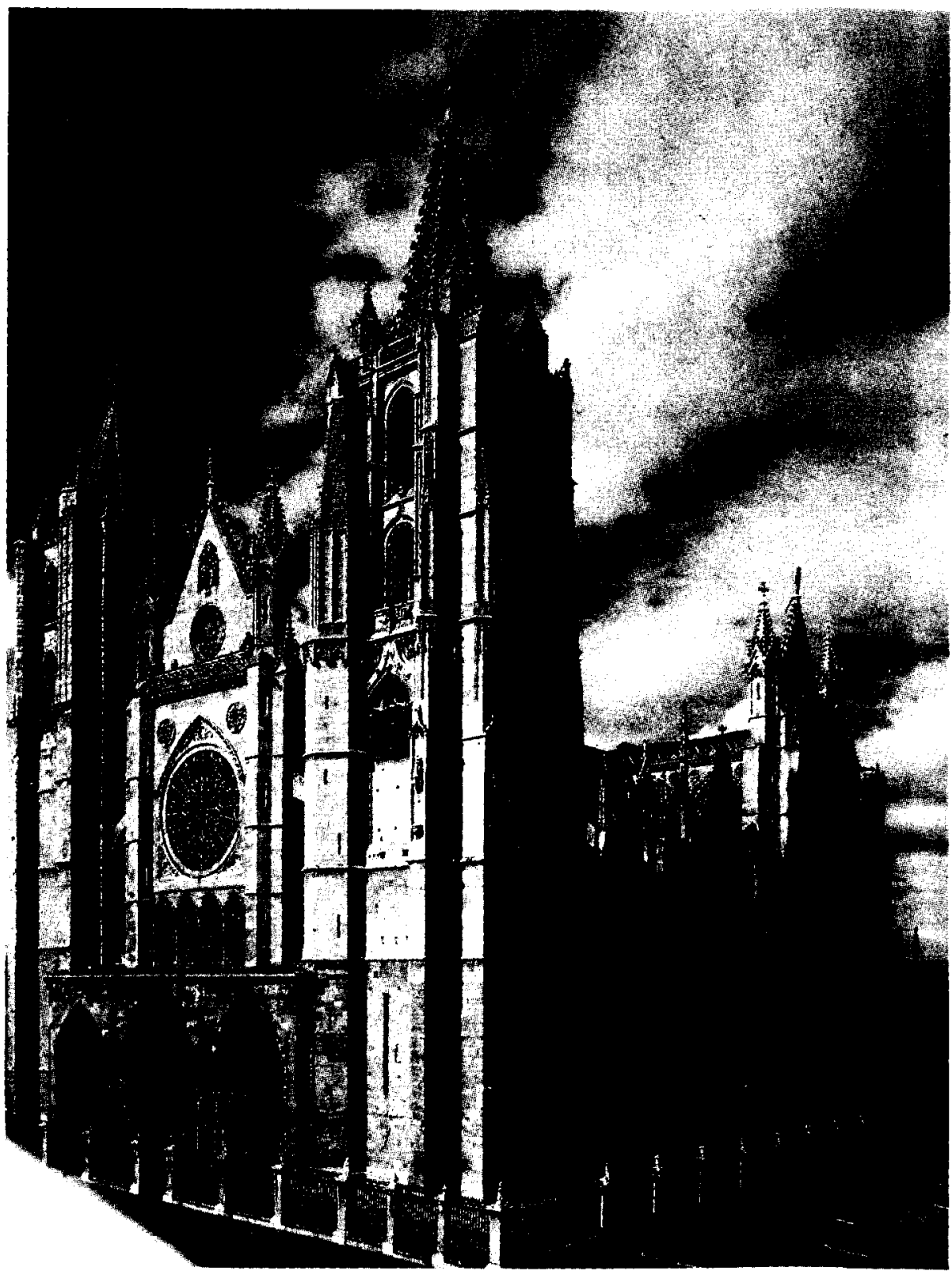

Fig. 10. Exterior de la Catedral de León. 
piración que su ascendiente Alfonso VII habia quebrado al repartir Castilla y León entre sus hijos D. Sancho y D. Fernando, demostraria el carácter superior de su gesta y de su propio estado como reino y como nación, frente a sus vecinos peninsulares. Universalizaria su hegemonia y prestigio aunque fuera más aparente que real. $Y$ es que, en realidad, el título imperial era más un distintivo de reputación, que el deseo de crear un imperio universal. En este caso, su iconografia en León estaria hispanizando unos atributos simbólicos. $Y$ asi, a título indicativo, es probable que este contrapeso al "fecho del Imperio", represente unas tendencias hegemónicas que situarían al monarca castellano por encima de los otros reyes, mientras que España quedaba identificada con Castilla.

Por lo demás, que estos proyectos imperiales fueran la historia de una desilusión, es algo que compete analizar a la propia Historia. En cualquier caso, sus intenciones son bien demostrativas de esa tendencia a la exaltación de una imagen de superioridad de los reyes de Castilla, desde que Alfonso VI tomara Toledo. $Y$ es en esta perspectiva cuando surge la Catedral de León, como sutil emblema de unas aspiraciones innovadoras pero basadas en la tradición. 
